\title{
Conicity index in people with hypertension followed in the Brazil's Family Health Strategy
}

Índice de conicidade em pessoas com hipertensão arterial acompanhadas pela Estratégia Saúde da Família Índice de conicidad en personas con hipertensión en seguimiento con la Estrategia de Salud Familiar

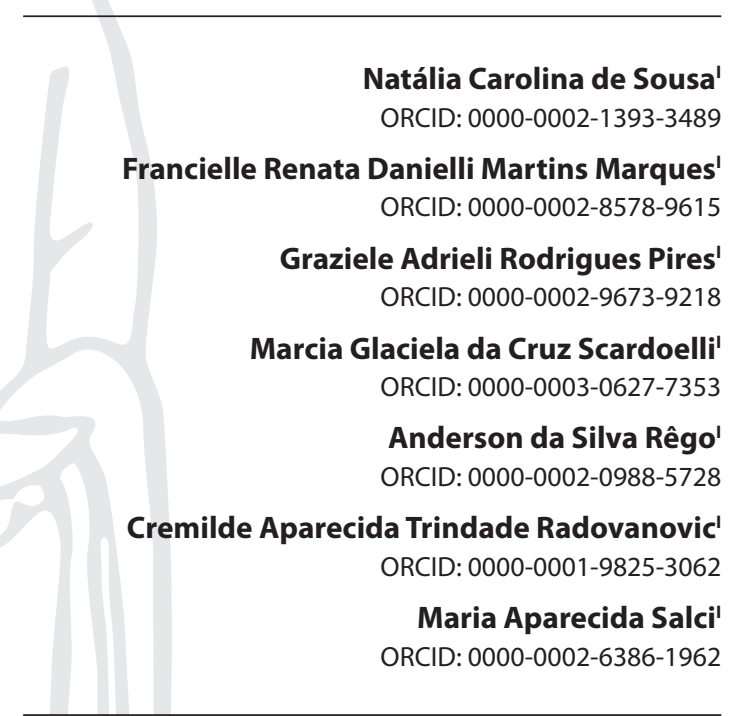

'Universidade Estadual de Maringá. Maringá. Paraná. Brazil.

How to cite this article: Sousa NC. Marques FRDM. Pires GAR. Scardoelli MGC. Rêgo AS. Radovanovic CAT. et al. Conicity index in people with hypertension followed in the Brazil's Family Health

Strategy. Rev Bras Enferm. 2020;73(5):e20190484 doi: http://dx.doi.org/10.1590/0034-7167-2019-0484

Corresponding author:
Anderson da Silva Rêgo
E-mail: anderson.dsre@hotmail.com

EDITOR IN CHIEF: Antonio José de Almeida Filho ASSOCIATE EDITOR: Hugo Fernandes

Submission: 06-24-2019

Approval: 12-19-2019

\begin{abstract}
Objectives: to analyze the conicity index in people with hypertension followed in the Brazil's Family Health Strategy. Methods: cross-sectional study conducted in a medium-sized municipality located in the state of Paraná. Data collection took place in the first semester of 2016. using an adapted and validated instrument. which addresses attributes of Primary Health Care. Sociodemographic and anthropometric variables and blood pressure were used in the study. The analysis of variance and linear regression was used to analyze the variables. Results: a total of 417 people participated in the study. most were women. elderly. married. with less than eight years of education and retired. Conicity index was prevalent in most of the study population. being significantly associated with the group of people with inadequate blood pressure control and high anthropometric parameters. Conclusions: most of the study participants had altered conicity index. especially those with inadequate blood pressure control.

Descriptors: Hypertension; Obesity Abdominal; Family Health Strategy; Anthropometry; Nursing
\end{abstract}

\section{RESUMO}

Objetivos: analisar o índice de conicidade em pessoas com hipertensão arterial acompanhadas pela Estratégia Saúde da Família. Métodos: estudo transversal. realizado em um município de médio porte localizado no estado do Paraná. Os dados foram coletados no primeiro semestre de 2016. utilizando instrumento adaptado e validado. que aborda atributos da Atenção Primária à Saúde. Neste estudo. foram utilizadas variáveis sociodemográficas. antropométricas e medidas de pressão arterial. Empregou-se a análise de variância e regressão linear para o tratamento das variáveis. Resultados: participação de 417 pessoas. a maioria mulheres. idosas. casadas. com menos de oito anos de estudo e aposentadas. $O$ índice de conicidade foi prevalente na maior parte da população estudada. com significativa associação ao grupo de pessoas com controle pressórico inadequado e parâmetros antropométricos elevados. Conclusões: a maioria dos participantes do estudo apresentou índice de conicidade alterado. principalmente as pessoas com controle pressórico inadequado.

Descritores: Hipertensão; Obesidade Abdominal; Estratégia Saúde da Família; Antropometria; Enfermagem.

\section{RESUMEN}

Objetivos: analizar el índice de conicidad en personas con hipertensión en tratamiento de seguimiento con la Estrategia de Salud Familiar. Métodos: estudio transversal realizado en un municipio de tamaño medio ubicado en el estado de Paraná. Los datos se recopilaron en el primer semestre de 2016. utilizando un instrumento adaptado y validado. que aborda los atributos de la Atención Primaria de Salud. En este estudio. se utilizaron las variables sociodemográficas. antropométricas y las mediciones de la presión arterial. El análisis de varianza y regresión lineal se utilizó para tratar las variables. Resultados: participación de 417 personas en el estudio. la mayoría mujeres. ancianos. casados. con menos de ocho años de estudio y jubilados. El índice de conicidad prevaleció en la mayoría de la población de estudio. con una asociación significativa con el grupo de personas con control inadecuado de la presión arterial y parámetros antropométricos altos. Conclusiones: la mayoría de los participantes en el estudio tenían un índice de variación alterado. especialmente aquellos con un control inadecuado de la presión arterial.

Descriptores: Hipertensión; Obesidad abdominal; Estrategia de Salud Familiar; Antropometría; Enfermería. 


\section{INTRODUCTION}

Obesity is defined as the excessive accumulation of body fat that affects health and well-being. Morbidity is an established risk factor for the onset of cardiovascular disease. hypercholesterolemia. diabetes mellitus. insulin resistance and hypertension. The strong association between weight gain and change in blood pressure values is identified in both genders and in different population groups. In Brazil. in 2017. the rate was $18.9 \%$ for obesity and $24.3 \%$ for hypertension. with higher prevalence in people with little education ${ }^{(1-3)}$.

Excessive fat is associated with the chance of having hypertension due to the relationship with different mechanisms that raise blood pressure levels. Some examples are altered hemodynamics. impaired sodium homeostasis. renal dysfunction. autonomic nervous system imbalance. endocrine changes. oxidative stress. inflammation and vascular injury. which lead to complications due to the chronicity of the pathology ${ }^{(4-5)}$.

Although obesity is a risk factor for other diseases. the distribution of adipose tissue in a specific site is superior to the total amount of body fat. and central obesity potentiates health problems. Faced with these questions. several anthropometric indicators were developed in order to simplify the assessment of body composition ${ }^{(6-7)}$.

Indicators are a practicable and easy to obtain method. low operating cost and effectiveness. They are widely used for the initial screening of obesity. hypertension and metabolic disorders in Primary Health Care $(\mathrm{PHC})$ services. done by professionals from the Family Health Strategy (FHS) teams. In addition. the indicators make it possible to know the risks of cardiovascular events in specific population groups. such as people undergoing hypertension treatment ${ }^{(2-3)}$.

The standard used internationally to diagnose general obesity in adults is body mass index $(\mathrm{BMI}) \geq 30 \mathrm{~kg} / \mathrm{m}^{2(8)}$. although this measure does not take into account the distribution of body fat ${ }^{(7-8)}$. The literature suggests several indexes for central obesity measurement. the most common being waist circumference (WC). waist-hip ratio (WHR) and waist-height ratio (WHtR). More recently. abdominal volume index $(\mathrm{AVI})$ and conicity index $(\mathrm{Cl})$ have been suggested ${ }^{(7-9)}$.

$\mathrm{Cl}$ was proposed in the 1990s. based on the hypothesis that people who accumulate fat around the abdominal area develop the shape similar to that of a double cone. The estimate of the index expresses the risk of diseases related to central obesity and is determined by measures of weight. height and WC. and is considered the best parameter to identify fat accumulation ${ }^{(10)}$. In practice. the verification of $\mathrm{Cl}$ is not yet popular among health professionals. due to the complexity of its mathematical equation and guidance on the procedures necessary to perform it ${ }^{(9)}$.

In this respect. $\mathrm{Cl}$ can be considered a useful. effective and specific tool for identifying cardiovascular risk ${ }^{(6.11)}$. diabetes mellitus. hypertension ${ }^{(12)}$ and metabolic syndrome ${ }^{(13)}$. Although $\mathrm{Cl}$ has potential value as a predictor of different conditions associated with obesity. the literature still slowly advances about its development. especially in relation to people already diagnosed and undergoing hypertension treatment. and in people with difficulties in adjusting blood pressure control. since they are at higher risk for cardiovascular events and require greater clarity in the physical examinations performed during their follow-up.

\section{OBJECTIVES}

To analyze the conicity index in people with hypertension followed by the Family Health Strategy.

\section{METHODS}

\section{Ethical aspects}

The study is part of a larger survey entitled "Assessing satisfaction of people with hypertension with primary health care services". The project of which this research is part followed the Resolution 466/2012 $2^{(14)}$ and was approved by the Standing Committee of Ethics in Research with Human Beings under opinion number 1.407.687/2016. The Informed Consent Form (ICF) was available in two copies of equal content. read and signed by all participants.

\section{Study design. setting and period}

Cross-sectional study conducted with people diagnosed and undergoing treatment for hypertension. enrolled in the SISHIPERDIA program of a medium-sized municipality located in the state of Paraná. Brazil. At the time of the study. the municipal health system had 34 Basic Health Units (BHU) and 71 FHS teams acting in a decentralized manner with $68 \%$ of population coverage $\mathrm{e}^{(15)}$.

Data collection took place in the first semester of 2016. from February to June. while PMC professionals provided assistance to people with hypertension. which took place in group meetings and routine appointments previously scheduled by the teams. Initially. prior contact was made with the directors of the BHU to present the objectives of the study. data collection method and request information on the frequency of SISHIPERDIA group meetings. The researchers organized the strategic planning for data collection.

Data collection was performed by three master's students and two undergraduates linked to scientific initiation projects of the nursing course. which belonged to the graduate program research group of a state university located in the municipality. Previous training was carried out to instruct on the content and completion of the instruments used in the study. anthropometric data collection and blood pressure measurements.

\section{Population and sample}

The initial sample of this study consisted of 437 people with hypertension who should meet the following inclusion criteria: 18 years of age or older. living in the urban area of the municipality. enrolled in the SISHIPERDIA program and have been attended by $\mathrm{BHU}$ health professionals in the last six months prior to data collection. Individuals without clinical conditions (speaking difficulties) to participate in the study. those who had not had previous consultations until the moment of data collection and pregnant women were excluded. since in PMC. they are fully attended by the care network to women's health during pregnancy and postpartum. and not by SISHIPERDIA.

The simple random sampling process was performed for sample selection. The sample size calculation considered a population of 
27.741. with an estimation error of $5 \%$ and a confidence interval of $95 \%$. plus $15 \%$ for possible losses. Consecutively. the stratified sample of users registered in each $\mathrm{BHU}$ included in the research was performed. The Municipal Health Office provided a list with name and code of the register in the internal system of the health care network. which served as the basis for a random draw according to the number of people served in each BHU. With the losses and refusals. the final sample consisted of 417 people.

\section{Study Protocol}

For data collection. two tools were used. The first evaluated the satisfaction of people with hypertension followed by FHS teams with the attributes of PMC. This instrument was built and validated in two states of northeastern Brazil. It is composed of four distinct parts. referring to sociodemographic. clinical and nutritional profile. family history. risk factors for hypertension and satisfaction with services provided by PMC ${ }^{(16)}$.

For this study. questions related to the sociodemographic profile were used. with the following variables: age. gender. race/ color schooling. occupation. marital status. clinical and nutritional profile. blood pressure measurements and anthropometric profile (weight. height. abdominal circumference and body mass index ${ }^{(16)}$. Also. the tool to assess socioeconomic status through household classification. created based on the Family Budget Survey (FBS) of the Brazilian Institute of Geography and Statistics (IBGE). with the levels categorized into AB. C and DE was used ${ }^{(17)}$.

The equipment used to measure anthropometric data and blood pressure values were well adjusted and calibrated. Analog scales with anthropometric ruler were used to check height and aneroid sphygmomanometers to measure blood pressure. To check the abdominal circumference. a non-elastic $150 \mathrm{~cm}$ tape measure was used. All anthropometric data collection procedures followed the recommendations of the Brazilian Association for the Study of Obesity and Metabolic Syndrome ${ }^{(8)}$.

As for blood pressure values. the guidelines provided by the VII Brazilian Guideline for Hypertension ${ }^{(18)}$ were followed. with proper technique and annotation. Values up to $139 / 89 \mathrm{mmHg}$ were considered adequate and values above 140/90 $\mathrm{mmHg}$ inadequate. To verify abdominal obesity. the waist/height ratio (WHtR) was calculated ${ }^{(19)}$ and the $\mathrm{Cl}$ was checked using the equation presented in Figure 1. The $\mathrm{Cl}$ cutoff points were defined from the altered values. being over 1.25 for the male population and 1.18 for the female population ${ }^{(20)}$.

$$
\mathrm{BI}=\frac{\text { Waist circumfere }(\mathrm{m})}{0.109 \sqrt{\frac{\text { Body weight }(\mathrm{kg})}{\text { Height }(\mathrm{m})}}}
$$

Figure 1 - Mathematical equation for the conicity index $(\mathrm{Cl})$ calculation. Maringá. Paraná. Brazil. 2016

\section{Results and statistics analysis}

Data were transferred to a spreadsheet. checked to identify and correct possible failures and double-typing to the Microsoft Excel 2016 spreadsheet. The analysis of variables was performed using the Statistical Package for the Social Sciences (SPSS) software. version 20.0. Data normality was identified by the KolmogorovSmirnov test. with Lilliefors correction.

As an independent variable. we used the $\mathrm{Cl}$ classification. dichotomized according to the established cutoff point and the categorization of blood pressure control as adequate and inadequate. For quantitative variables. the Mann-Whitney test was used for analysis of variance. obtaining the mean and standard deviation of the variables. and to compare differences between parametric and independent sample means.

To verify the correlation between the $\mathrm{Cl}$ and the variables related to blood pressure control. the dispersion diagram was used. assuming the hypothetical model of . in which y represents the continuous values of the $\mathrm{Cl}$ and the continuous values of blood pressure. After the calculation. the linear regression analysis was performed from the equation $y$. to assign the trend line to the scatter plot. to establish the determination coefficient $\left(R^{2}\right)$ and to verify the variability of the resulting data of this analysis. The diagnosis of independence of the variables was verified through the Durbin-Watson test. in which it presented absence of autocorrelation. Significant $p<0.05$ was considered for all tests performed.

\section{RESULTS}

A total of 417 people diagnosed with hypertension participated in the study. Most elderly (62.4\%). female (67.9\%). with less than eight years of education (80.8\%). white (62.4\%). living with a partner (58.3\%). retired/pensioner (55.2\%) and belonging to the C income group (4 - 10 Brazilian Minimum wage) middle class (43.9\%). According to the $\mathrm{Cl}$ classification. sociodemographic characteristics showed the same direction. with differences in percentage and absolute values (Table 1).

Table 2 presents anthropometric measurements and blood pressure values. Systolic blood pressure (SBP) had a higher mean in inadequate blood pressure control parameters in both normal (149.1 \pm 13.79$)$ and altered (148.6 \pm 16.9$)$ Cls. with significant differences. For diastolic blood pressure (DBP). weight and height. despite the different means. no statistical significance was observed. A statistical difference in BMI was identified in the altered $\mathrm{Cl}$. in which people with inadequate blood pressure control had a higher average $(30.1 \pm 5.4)$ and with statistical significance compared to the appropriate blood pressure control.

The WHtR also showed differences in altered $\mathrm{Cl}$. in which people with inadequate blood pressure control $(64.7 \pm 7.1)$ tend to have a higher average. Waist circumference differed in the two $\mathrm{Cl}$ classifications. in which people with inadequate blood pressure control tended to have significant changes in WC (85.4 $\pm 10.1 / 103.1 \pm 12.9)$. The continuous $\mathrm{Cl}$ variable showed statistical difference in the dichotomous classification of the same variable. where even in people with normal $\mathrm{Cl}$. the mean was higher among those with inadequate blood pressure control (1.18 \pm 0.3 ) (Table 2).

Figure 2 shows the dispersion diagrams between $\mathrm{Cl}$ and SBP values. noting that the higher the $\mathrm{Cl}$ values. the higher the variable parameters will be. The trend line remained straight in diagrams "b". "c" and " $d$ ". which is the variability of pressure and $\mathrm{Cl}$ values. in which it is not possible to predict a fixed characteristic of the 
data. In diagram "a". the line presented a small slope and $\mathrm{R}^{2}$ with a value of 0.2318 . which can be explained by the small number of the stratified individuals with normal $\mathrm{Cl}$.

Figure 3 shows the variation between the $\mathrm{Cl}$ and DBP values. which has the same follow-up. that the higher the $\mathrm{Cl}$. the higher the blood pressure value. The trend line does not show significant inclination in the diagrams. which supports the interpretation that altered $\mathrm{Cl}$ is higher in people with inadequate blood pressure control. $\mathrm{R}^{2}$ also did not present values close to one. only in diagram "a". where it is possible to observe a small difference in values due to the reduced number of stratified people with normal $\mathrm{Cl}$.

Table 1 - Sociodemographic profile of people with hypertension followed in the Brazil's Family Health Strategy. according to the conicity index classification. Maringá. Paraná. Brazil. 2016

\begin{tabular}{|c|c|c|c|}
\hline & \multirow[b]{2}{*}{$\begin{array}{l}\text { Total } \\
\text { n (\%) }\end{array}$} & \multicolumn{2}{|c|}{ Conicity index } \\
\hline & & $\begin{array}{c}\text { Normal } \\
(n=24) \\
n(\%)\end{array}$ & $\begin{array}{c}\text { Altered } \\
(n=393) \\
n(\%)\end{array}$ \\
\hline \multicolumn{4}{|l|}{ Age } \\
\hline$\leq 59$ years & $157(37.6)$ & $5(3.2)$ & $152(96.8)$ \\
\hline$\geq 60$ years & $260(62.4)$ & $19(7.3)$ & $241(92.7)$ \\
\hline \multicolumn{4}{|l|}{ Gender } \\
\hline Male & $134(32.1)$ & $14(10.4)$ & $120(89.6)$ \\
\hline Female & $283(67.9)$ & $10(3.5)$ & $273(96.5)$ \\
\hline \multicolumn{4}{|l|}{ Education } \\
\hline$\leq 8$ years & $337(80.8)$ & $20(5.9)$ & $317(94.1)$ \\
\hline$>8$ years & $80(19.2)$ & $4(5.0)$ & $76(95.0)$ \\
\hline \multicolumn{4}{|l|}{ Race/Color } \\
\hline White & $260(62.4)$ & $12(4.6)$ & $248(95.4)$ \\
\hline Non-white & $157(37.6)$ & $12(7.6)$ & $145(92.4)$ \\
\hline \multicolumn{4}{|l|}{ Marital Status } \\
\hline With a partner & $243(58.3)$ & $15(6.2)$ & $228(93.8)$ \\
\hline Withouta partner & $174(41.7)$ & $9(5.2)$ & $165(94.8)$ \\
\hline \multicolumn{4}{|l|}{ Income group } \\
\hline$A B$ & $148(35.5)$ & $8(5.4)$ & $140(94.6)$ \\
\hline$C$ & $183(43.9)$ & $10(5.5)$ & $173(94.5)$ \\
\hline $\mathrm{DE}$ & $86(20.6)$ & $6(7.0)$ & $80(93.0)$ \\
\hline \multicolumn{4}{|l|}{ Ocupation } \\
\hline Employee & $96(23.0)$ & $6(6.2)$ & $90(93.8)$ \\
\hline Unemployed & $91(21.8)$ & $4(4.4)$ & $87(95.6)$ \\
\hline Retired/Pensioner & $230(55.2)$ & $14(6.1)$ & $216(93.9)$ \\
\hline
\end{tabular}

\section{DISCUSSION}

The main results found in the present study revealed that the higher the $\mathrm{Cl}$ values. the higher the SBP and DBP measurements. where the altered $\mathrm{Cl}$ is higher in people with inadequate blood pressure control. In addition. people with altered $\mathrm{Cl}$ and inadequate blood pressure control presented changes in BMI. WHtR and WC parameters.

Indirect identification of hypertension through anthropometric indicators is an important public health strategy tool to favor the identification of changes in blood pressure measurement values ${ }^{(3)}$. The results found in this study verified that $\mathrm{Cl}$ is a useful and inexpensive monitoring instrument in blood pressure control for use in PMC in addition to other actions taken to identify the precise diagnosis and treatment-resolving interventions.

The literature provides studies on the subject related to $\mathrm{Cl}$ as a predictor of changes in anthropometric parameters. used as an indicator to identify the diagnosis of cardiovascular events. without specifying whether the risk is inherent in the chronicity of hypertension and diseases of the metabolic system. such as diabetes mellitus. This research shows results in people already diagnosed and undergoing treatment for hypertension. in which most presented changes in $\mathrm{Cl}$ parameters. in association with other anthropometric measurements and the variable regarding blood pressure adequacy.

$\mathrm{Cl}$ is not yet a usual practice. certainly due to the lack of knowledge of its predictive value of cardiovascular risk. especially in PMC. where there are greater health actions for the population with hypertension ${ }^{(4.10-11)}$. From this perspective. the literature approaches $\mathrm{Cl}$ as an important factor for the diagnosis of hypertension. as an indicator that may favor the identification of potential factors in the difficulty of adjusting blood pressure control and determinants related to its chronicity ${ }^{(4.11)}$.

Studies show that characteristics such as advanced age and gender/ethnicity contribute to the increase of BP and the development of hypertension. as well as other aggravating factors also favor the development of comorbidity. for example. overweight and obesity. When assessing the socioeconomic profile of the population with hypertension under study. the data are similar to the results found in national and international research.
Table 2 - Anthropometric and blood pressure measurements according to the conicity index classification and adequacy of blood pressure control of people with hypertension followed in the Brazil's Family Health Strategy. Maringá. Paraná. Brazil. 2016

\begin{tabular}{|c|c|c|c|c|c|c|c|}
\hline & \multirow{2}{*}{$\begin{array}{l}\text { Total } \\
\mathrm{M} \pm \mathrm{SD}\end{array}$} & \multicolumn{2}{|c|}{ Normal Conicity Index } & \multicolumn{4}{|c|}{ Altered Conicity Index } \\
\hline & & $\begin{array}{c}\text { Adequate } \\
\mathrm{M} \pm \mathrm{SD}\end{array}$ & $\begin{array}{c}\text { Inadequate } \\
M \pm S D\end{array}$ & $p$ & $\begin{array}{l}\text { Adequate } \\
M \pm S D\end{array}$ & $\begin{array}{l}\text { Inadequate } \\
\mathrm{M} \pm \mathrm{SD}\end{array}$ & $p$ \\
\hline SBP & $103.0 \pm 19.0$ & $120.8 \pm 7.9$ & $149.1 \pm 13.79$ & 0.024 & $119.4 \pm 10.3$ & $148.6 \pm 16.9$ & 0.000 \\
\hline DBP & $81.8 \pm 11.6$ & $78.0 \pm 5.1$ & $90.0 \pm 7.3$ & 0.570 & $75.0 \pm 8.4$ & $89.4 \pm 10.5$ & 0.180 \\
\hline Weight & $74.9 \pm 16.2$ & $73.4 \pm 16.3$ & $69.0 \pm 21.4$ & 0.677 & $73.7 \pm 15.1$ & $76.8 \pm 17.6$ & 0.112 \\
\hline Height & $1.59 \pm 0.8$ & $1.65 \pm 0.9$ & $1.61 \pm 0.7$ & 0.764 & $1.59 \pm 0.8$ & $1.59 \pm 0.8$ & 0.605 \\
\hline BMI & $29.2 \pm 5.3$ & $26.2 \pm 6.7$ & $27.0 \pm 6.8$ & 0.515 & $28.7 \pm 5.0$ & $30.1 \pm 5.4$ & 0.012 \\
\hline WHtR & $62.8 \pm 8.1$ & $49.08 \pm 7.1$ & $51.8 \pm 7.4$ & 0.081 & $62.6 \pm 7.3$ & $64.7 \pm 7.1$ & 0.007 \\
\hline$A C$ & $100.3 \pm 13.2$ & $79.4 \pm 13.8$ & $85.4 \pm 10.1$ & 0.037 & $100.6 \pm 12.0$ & $103.1 \pm 12.9$ & 0.016 \\
\hline $\mathrm{Cl}$ & $1.35 \pm 0.10$ & $1.12 \pm 0.9$ & $1.18 \pm 0.3$ & 0.012 & $1.35 \pm 0.9$ & $1.37 \pm 0.9$ & 0.103 \\
\hline
\end{tabular}

Note:DBP:Diastolic Blood Pressure; SBP: Systolic Blood Pressure; BMI:Body Mass Index; AC:Abdominal Circumference; M:Mean; SD:Standard Deviation; Cl:Conicity Index; WHtR: Waist/height ratio. in which the same specificities are observed (21-22).

Regarding gender and age. females and advanced age were more prevalent in this study. Research points that this result may be associated with female life behavior. since women are more likely to seek specialized medical help. and thus are more frequently diagnosed when compared to males. In addition. the female population often participates in activities aimed at prevention and health promotion ${ }^{(23)}$.

Interest in this population group was found in other studies using $\mathrm{Cl}$ and its relationship with the development of hypertension and other 


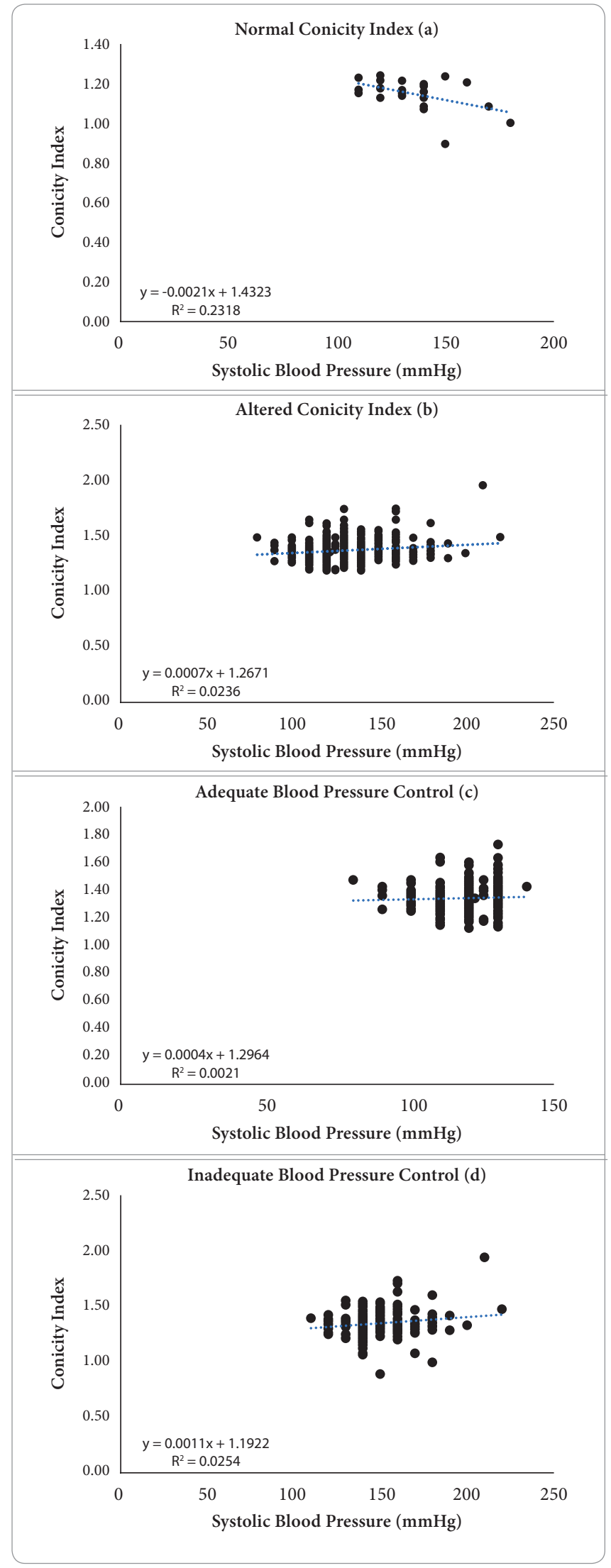

Figure 2 - Variation in diastolic blood pressure according to the classification of the conicity index and adequacy of blood pressure control of people with hypertension followed in the Brazil's Family Health Strategy. Maringá. Paraná. Brazil. 2016

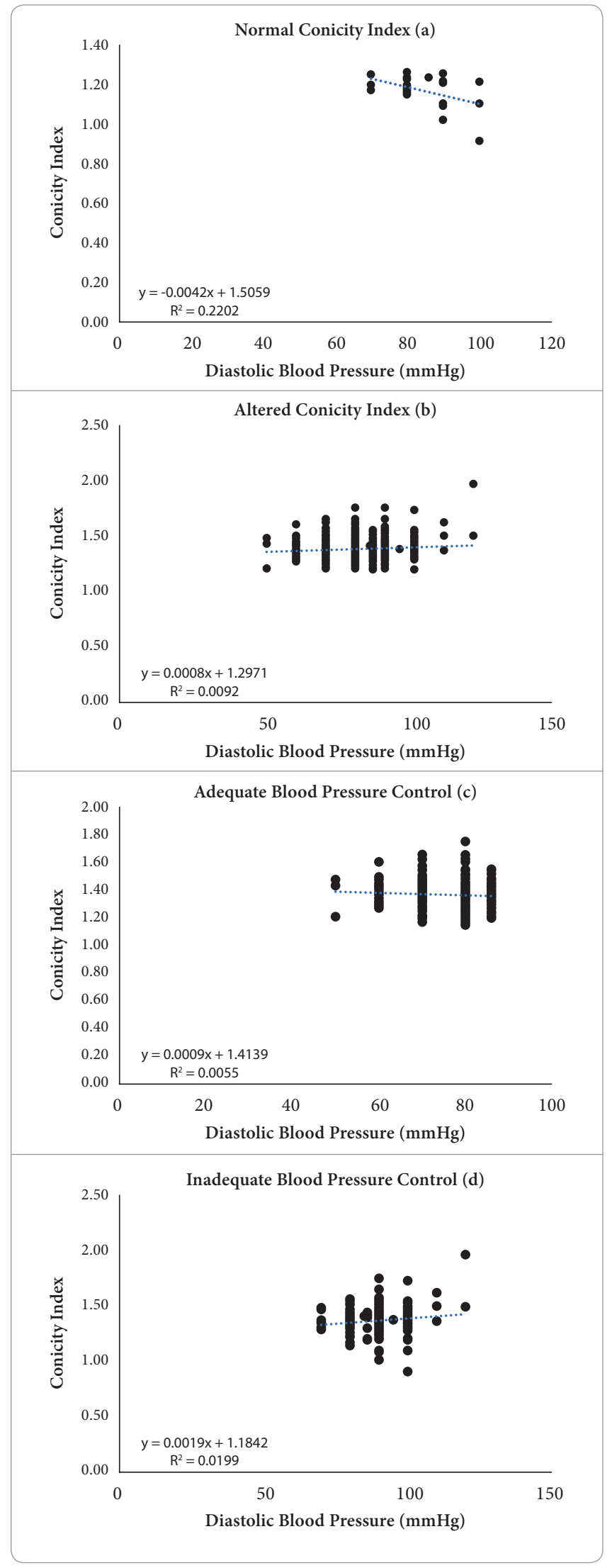

Figure 3 - Variation in diastolic blood pressure according to the conicity index classification and adequacy of blood pressure control of people with hypertension followed in the Brazil's Family Health Strategy. Maringá. Paraná. Brazil. 2016 
pathologies. A study conducted in Rio Grande do Sul with climacteric women registered at the FHS of the BHU found that all participants had a high cardiovascular risk due to hypertension through $\mathrm{Cl}$. with a higher average of this index in those who were in the postmenopausal period $(1.25 \pm 0 ; 0 / 1.19 \pm 0.9)$. also pointing to the age issue ${ }^{(11)}$.

Research conducted with women in São Paulo confirmed the association of $\mathrm{Cl}$ with diabetes mellitus and hypertension. Compared with the group with $\mathrm{Cl}<75$. study participants had a higher risk of developing diabetes mellitus and hypertension. Results showed that the negative impact of age in these associations significantly increased the chances of women presenting risks for the aforementioned diseases. These results are linked to metabolic changes inherent to the physiological condition of women and may change the drugs mechanism of action and issues related to blood pressure control activities ${ }^{(12)}$.

In other studies. the male population has a higher prevalence of hypertension $^{(7)}$ and risk for cardiovascular disease ${ }^{(9)}$. In this sense. it is also necessary to develop health actions focused on this population. aiming at the early detection of future health problems. The scientific evidence that hypertension has a higher association with $\mathrm{Cl}$ in women than $\operatorname{men}^{(7)}$ shows the need for research in populations with different characteristics. in order to meet the needs and demands of the population. with precise and resolute interventions.

For this research. people with altered $\mathrm{Cl}$ and inadequate blood pressure control also presented alterations in anthropometric measurements of BMI and WHtR. These findings corroborate studies in which the accumulation of body fat resulted in higher sodium retention. justifying the fact that people with altered BMI and WHtR have higher SBP and DBP values ${ }^{(24)}$. In addition. the association found corroborates the literature. since such anthropometric indicators are related to hypertension. $\mathrm{BMI}$ and $\mathrm{WHtR}$. the measures used to obtain the $\mathrm{Cl}^{(25)}$. Other studies in different populations have already found that overweight people have statistically higher blood pressure values ${ }^{(3.24)}$.

In linear regression analysis. high SBP and DBP values are associated with people with altered $\mathrm{Cl}$. These findings corroborate a study that used linear correlation analysis and found that the $\mathrm{Cl}$. as well as the other anthropometric parameters. correlated positively with blood pressure levels and more significantly with diastolic blood pressure ${ }^{(25)}$.

A study that is part of the project ELSA (Longitudinal Study of Adult Health) addressed the issue of anthropometric parameters in the identification of metabolic alterations and possible cardiovascular complications arising from chronic diseases. added by obesity. Unpopular parameters such as $\mathrm{Cl}$ need to have evidence as a timely method of cardiovascular risk verification. especially in PMC. conducted by the FHS. where consultations. routine examinations and periodic follow-up of these people are performed $^{(26)}$.

An American study indicated $\mathrm{Cl}$ as the best predictor of cardiovascular events over a 10-year period. compared to central obesity parameters (waist circumference. waist/hip ratio and waist/height ratio) and the current abdominal volume index ${ }^{(9)}$. A protocol for monitoring people with hypertension in PMC has recently been created. addressing issues related to anthropometric profile. However. it does not include mathematical equations to identify and classify central obesity. which makes it incipient for people with the morbidity ${ }^{(27)}$.

Few studies address the $\mathrm{Cl}$. its sensitivity and specificity in relation to blood pressure values. especially in people who treat the disease. highlighting the need for further research addressing the issue with the same specific population. Studies on cardiovascular risk determination methods based on anthropometry and lipid values ${ }^{(19.24-26)}$ confirm the findings of this study.

It is important to highlight that the results presented in this study show that more than $94 \%$ of respondents presented changes in the $\mathrm{Cl}$ parameters. This result enhances the importance of this research in sensitizing health professionals about the relevance of anthropometry in the identification of cardiovascular risk and the relationship between central obesity indexes and blood pressure inadequacy. encouraging new interventions to be created with resolutive power of this public health problem.

Governmental spheres are expected to work incisively with financial investment to develop new studies on the inclusion of anthropometric measurements and blood pressure values. with a view to enhancing the creation of new methods for early identification of the risk of developing cardiovascular events. This may support the interventions needed to reduce hospitalizations and financial costs and assistance for chronic disease complications.

\section{Study limitations}

The limitation of this research was the impossibility of attributing chance to the results due to the nature of cross-sectional studies. as well as the fact that it took place in a medium-sized municipality and in a specific region. which may reduce its generalization potential. However. it presents pertinent and incisive results for new practices and new studies to control anthropometric parameters. mainly due to their easy replication.

\section{Contributions to the fields of nursing. health or public policy}

The main contribution of this study is the findings that demonstrate the possibility of using $\mathrm{Cl}$ as an alternative anthropometric indicator to monitor cardiovascular risk. especially in people who present changes in blood pressure within PMC. The implementation of effective low-cost and easy-to-use measures can contribute to accurate and resolute care for both the medical team and the nursing team. as they are. in most cases. responsible for the care of the population undergoing hypertension treatment and for checking this population's anthropometric data.

Regarding public health policies. the study advances in the monitoring issues of people undergoing treatment for hypertension. as well as in the systemic assessment of the risk of cardiovascular events. using anthropometric measurements and blood pressure values that must be constantly checked. The study also opens up new perspectives for research on the theme and implementation of new health actions aimed at reducing health inequities. preventing disease-related diseases and improving the population's quality of life. 


\section{CONCLUSIONS}

Based on the results found. we can conclude that most of the study participants had altered $\mathrm{Cl}$. both in the appropriate and inadequate blood pressure control group. Results also showed changes in BMI. WC and WHtR. with statistical significance in the group of people with inadequate blood pressure control. Although not directly related to inadequate blood pressure values. anthropometric parameters are widely discussed in the literature as risk indicators for the diagnosis of hypertension and cardiovascular events linked to the chronicity of the disease.

The possibility of adding body mass and height in the Cl calculation formula makes the indicator an important tool for measuring the risk of cardiovascular events by considering total body mass. This measure can be easily incorporated into the periodic evaluation performed by the FHS professionals in PMC. mainly due to its low cost. easy applicability and visibility to the parameters. for longitudinal follow-up of people with hypertension treated at this level of care.

\section{REFERENCES}

1. Ministério da Saúde (BR). Secretaria de Vigilância em Saúde. Departamento de Vigilância de Doenças e Agravos não Transmissíveis e Promoção da Saúde. Vigitel Brasil 2017: vigilância de fatores de risco e proteção para doenças crônicas por inquérito telefônico: estimativas sobre frequência e distribuição sociodemográfica de fatores de risco e proteção para doenças crônicas nas capitais dos 26 estados brasileiros e no Distrito Federal em 2017. Brasília: Ministério da Saúde. 2018.

2. Ononamadu CJ. Ezekwesili CN. Onyeukwu OF. Umeoguaju UF. Ezeigwe OC. Ihegboro GO. Comparative analysis of anthropometric indices of obesity as correlates and potential predictors of risk for hypertension and prehypertension in a population in Nigeria. Cardiovasc J Africa 2017; 28:92-9. doi: 10.5830/CVJA-2016-061

3. Diniz KDO. Rocha SV. Oliveira ACC. Anthropometric indicators of obesity such as predictors of high blood pressure in the elderly. Braz J Kinanthropometr Hum Perform. 2017;19:31. doi: 10.5007/1980-0037.2017v19n1p31

4. Ryu S. Frith E. Pedisic Z. Kang M. Loprinzi PD. Secular trends in the association between obesity and hypertension among adults in the United States. 1999-2014. Europ J Intern Med. 2019;62:37-42. doi: 10.1016/j.ejim.2019.02.012

5. Susic D. Varagic J. Obesity. Med Clin North Am. 2017;101:139-57. doi: 10.1016/j.mcna.2016.08.008

6. Pohl HH. Arnold EF. Dummel KL. Cerentini TM. Reuter EM. Reckziegel MB. Anthropometric indicators and cardiovascular risk factors in rural workers. Rev Bras Med Esporte. 2018;24:64-8. doi: 10.1590/1517-869220182401158030

7. Dhall M. Devi KS. Nilupher. Gupta U. Tyagi R. Kapoor S. Hypertension and its correlate with general and central adiposity: a study among urban population of Delhi. Diabetes Metabol Syndrome: Clin Res Reviews. 2018;12:881-4. doi: 10.1016/j.dsx.2018.05.008

8. Associação Brasileira para o Estudo da Obesidade e da Síndrome Metabólica (ABESO). Diretrizes brasileiras de obesidade 2016. $4^{\mathrm{a}}$ ed. [Internet] São Paulo (SP);2016 [cited 2019 May 25]. Available from: http://www.abeso.org.br/uploads/downloads/92/57fccc403e5da.pdf

9. Motamed N. Perumal D. Zamani F. Ashrafi H. Haghjoo M. Saeedian FS. et al. Conicity index and waist-to-hip ratio are superior obesity indices in predicting 10-year cardiovascular risk among men and women: obesity indices and 10-year CV risk. Clin Cardiol. 2015; 38:527-34. doi: $10.1002 / \mathrm{clc} .22437$

10. Valdez R. A simple model-based index of abdominal adiposity. J Clin Epidemiol. 1991;44:955-6. doi: 10.1016/0895-4356(91)90059-I

11. Dallazen F. Winkelmann ER. Berlezi EM. Cardiovascular risk evaluated by the conicity index in climacteric women: a comparative analysis between the pre and post-menopause periods. Scient Med. 2017; 27:28268. doi: 10.15448/1980-6108.2017.4.28268

12. Andrade MD. Freitas MCP. Sakumoto AM. Pappiani C. Andrade SC. Vieira VL. et al. Association of the conicity index with diabetes and hypertension in Brazilian women. Arch Endocrinol Metabol. 2016;60:436-42. doi: 10.1590/2359-3997000000187

13. Nobre RS. Guimarães MR. Batista AMO. Sousa AF. Lima LHO. Silva ARV. Anthropometric indicators that predict metabolic syndrome among adolescents. Texto Contexto Enferm. 2018;27. doi: 10.1590/0104-070720180005270016

14. Conselho Nacional de Saúde (BR). Resolução número 466. de 12 de dezembro de 2012. Brasília. 2012.

15. Ministério da Saúde (BR). Departamento de Atenção Básica (DAB). Histórico de Cobertura da Saúde da Família [Internet]. Brasília. DF. 2016 [cited 2019 May 25]. Available from: http://dab.saude.gov.br/portaldab/historico_cobertura_sf.php

16. Paes NA. Silva CS. Figueiredo TMRM. Cardoso MAA. Lima JO. Satisfação dos usuários hipertensos com os serviços da rede de atenção primária no Brasil: um estudo de validação. Rev Panam Salud Publica [Internet]. 2014[cited 2019 May 25];36(2):87-93. Available from: http:// www.scielosp.org/pdf/rpsp/v36n2/03.pdf

17. Associação Brasileira de Empresas de Pesquisa. Adoção do CCEB 2008: Critério de Classificação Econômica Brasil. São Paulo: ABEP; 2015.

18. Malachias MVB. Souza WKSB. Plavnik FL. Rodrigues CIS. Brandão AA. Neves MFT. et al. Sociedade Brasileira de Cardiologia. 7a Diretriz Brasileira de Hipertensão Arterial. Arq Bras Cardiol [Internet]. 2016[cited 2019 May 25];107(3). Available from: http:// www.scielo.br/pdf/abc/ v107n3s3/0066-782X-abc-107-03-s3-0067.pdf

19. Ashwell M. Hsieh SD. Six reasons why the waist-to-height ratio is a rapid and effective global indicator for health risks of obesity and how its use could simplify the international public health message on obesity. Int J Food Sci Nutrition 2005; 56:303-7. doi: $10.1080 / 09637480500195066$ 
20. Pitanga FJG. Lessa I. Sensitivity and specificity of the conicity index as a coronary risk predictor among adults in Salvador. Brazil. Rev Bras Epidemiol. 2004;7:259-69. doi: 10.1590/S1415-790X2004000300004

21. Ghazi L. Oparil S. Calhoun DA. Lin CP. Dudenbostel T. Distinctive risk factors and phenotype of younger patients with resistant hypertension: age is relevant. Hypertension. 2017;69:827-35. doi: 10.1161/HYPERTENSIONAHA.116.08632

22. Almeida AS. Moura JP. Rossi VEC. Piantino CB. Lifestyle and socioeconomic profile of hypertensive patients. Rev Enferm UFPE. 2017;11:4826. doi: 10.5205/1981-8963-v11i12a222299p4826-4837-2017

23. Silva SSBE. Oliveira SFSB. Pierin AMG. The control of hypertension in men and women: a comparative analysis. Rev Esc Enferm USP. 2016;50(1):50-8. doi: 10.1590/S0080-623420160000100007

24. Pinto ADA. Claumann GS. Amaral LC. Pelegrini A. Prevalence of high blood pressure among adolescents and association with anthropometric indicators. Medicina. 2017;50:237. doi: 10.11606/issn.2176-7262.v50i4p237-244

25. Padilha BM. Diniz ADS. Ferreira HDS. Oliveira Tomiya MT. Cabral PC. Anthropometric predictors of hypertension in afro-descendant women. Scient Med. 2017;27:27527. doi: 10.15448/1980-6108.2017.3.27527

26. Eickemberg M. Amorim LDAF. Almeida MCC. Aquino EML. Fonseca MJM. Santos IS.. et al. Indicadores de Adiposidade Abdominal e Espessura da Intima-Média Carotídea: Resultados do Estudo Longitudinal da Saúde do Adulto (ELSA-Brasil). Arq Bras Cardiol. 2019;112(3):220-7. doi: 10.5935/ abc.20180273

27. Dantas RCO. Roncalli AG. Protocol for hypertensive individuals assisted in Basic Health Care. Ciênc Saúde Coletiva. 2019;24: 295-306. doi: 10.1590 / 1413-81232018241.35362016 